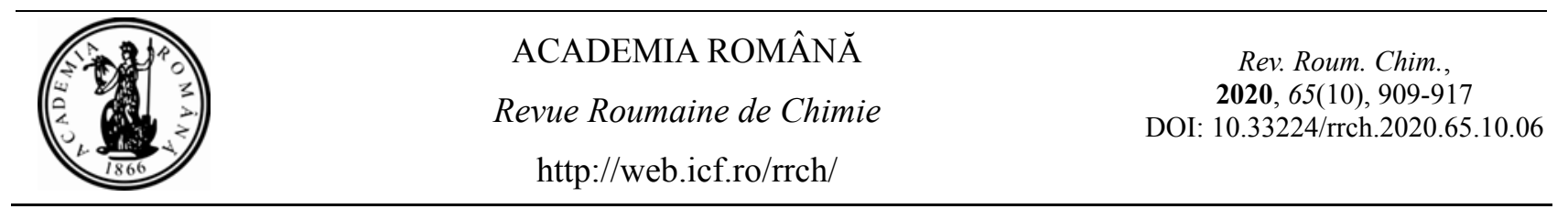

\title{
ALKALI FUSION CO-PRECIPITATION/CATION EXCHANGE/EXTRACTION ENRICHMENT FOR DETERMINATION OF TRACE RARE EARTH ELEMENTS IN ROCKS BY INDUCTIVELY COUPLED PLASMA MASS SPECTROMETRY
}

\author{
Wenzhi ZHAO, ${ }^{*}$ Chuanfang ZHOU, Bing LU, Junbo YU and Yuan ZHANG \\ Center for Harbin Natural Resources Comprehensive Survey, China Geological Survey, \\ Harbin, 150039, P. R. China
}

In this paper, three separation and pre-enrichment methods of $\mathrm{Mg}(\mathrm{OH})_{2}$ and $\mathrm{Fe}(\mathrm{OH})_{3}$ co-precipitation, cation exchange and 1-phenyl-3-methyl-4benzoyl-pyrazolone (PMBP) extraction were established by sodium peroxide alkali fusion digestion. $\mathrm{Ca}, \mathrm{Na}$ and $\mathrm{K}$, etc. were virtually eliminated from the analysis solutions using three sample processing procedures, thereby avoiding potential matrix interference and mass spectrometry interference due to high salt content. The detection limits of three methods were 0.0009 $0.0076 \mathrm{mg} / \mathrm{kg}, 0.0011-0.0062 \mathrm{mg} / \mathrm{kg}, 0.0023-$ $0.0114 \mathrm{mg} / \mathrm{kg}$, respectively; the relative deviations of the determined rare earth elements (REEs) were $-6.9-7.6 \%,-9.1-6.6 \%$ and $-8.4-12.3 \%$, respectively. The $\%$ RSD values of the three methods were lower than $10 \%$, demonstrating good precision. The fit for purpose of the results was also evaluated by the quality criteria test proposed by the International Geological Correlation Programme (IGCP), from which it can be deduced that the three methods were adequate considering geochemical mapping application. The three sample processing procedures can be applied for the determination of rare earth elements in rocks.

\section{INTRODUCTION}

Rare earth elements (REEs) have similar geochemical characteristics, stable chemical properties and high degree of uniformity. This unique geochemical property is often used to study mineral sources, evolution processes, rock genesis and magmatism, reflecting the element migration, enrichment and environmental change during the formation of geological bodies. ${ }^{1-3}$ Therefore, there is a deep necessity for research in the determination and distribution of trace lanthanides in rocks. The physical and chemical properties of REEs are very similar and they are also closely symbiotic in nature. Therefore, REEs are often considered as a whole. However, the characteristics that distinguish each REE from other REEs cannot be ignored. ${ }^{-5}$

The term REEs is related to the elements of Group 3 in the Periodic Table: Sc, Y and the lanthanides, which comprises a group of 15 elements from La to Lu. However, Pm does not occur in the nature. Rare earth elements exist predominantly in the trivalent oxidation state. Sm, $\mathrm{Eu}$ and $\mathrm{Y}$ can be reduced to bivalent state and $\mathrm{Ce}$, $\mathrm{Pr}$ and $\mathrm{Tb}$ can be oxidized to tetravalent state depending on the redox conditions. REEs are

\footnotetext{
*Corresponding author: zhaowenzhi817@163.com
} 
classified according to the separation process, and they can be divided into light REEs (LREEs), including $\mathrm{La}, \mathrm{Ce}, \mathrm{Pr}, \mathrm{Nd}, \mathrm{Pm}, \mathrm{Sm}, \mathrm{Eu}$ and heavy REEs (HREEs), including Gd, Tb, Dy, Ho, Er, Tm, $\mathrm{Yb}, \mathrm{Lu}, \mathrm{Y}^{6,7}$

At present, the determination of REEs mainly uses neutron activation analysis (NAA), ${ }^{8,9}$ inductively coupled plasma mass spectrometry (ICP-MS), ${ }^{10-13}$ inductively coupled plasma emission spectrometry (ICP-OES $)^{14,15}$ and X-ray fluorescence spectrometry (XRF). ${ }^{16,17}$ ICP-MS is widely used in the analysis of REEs in geological samples due to its high sensitivity, low detection limit and wide linear dynamic range ${ }^{18-20}$ However, the direct determination of REEs in rocks is still difficult for various reasons. The content of REEs in some polymetallic ores is very low $(0.1-1 \mathrm{mg} / \mathrm{kg})$, while the content of matrix elements $(\mathrm{Mg}, \mathrm{Fe}, \mathrm{Na}, \mathrm{Ca}$, etc.) is very high. Using conventional sample preparation methods such as alkali melting, microwave digestion, mixed acid digestion and high pressure closed digestion to analyze by ICP-MS, generally needs multiple dilution (1000 times), which will lower the content of trace REEs bellow the detection limit of the instrument, therefore the content of REEs cannot be accurately analyzed. ${ }^{21,22}$

In this paper, sodium peroxide $\left(\mathrm{Na}_{2} \mathrm{O}_{2}\right)$ alkali melting digestion was used. $\mathrm{Mg}(\mathrm{OH})_{2}$ and $\mathrm{Fe}(\mathrm{OH})_{3}$ co-precipitation, and enrichment by cation exchange or PMBP extraction were selected to separate REEs from other rock-forming elements ( $\mathrm{Mg}, \mathrm{Fe}, \mathrm{Na}, \mathrm{Ca}$, etc.), avoiding potential matrix interference and mass spectrometry interference caused by high salt content. The effects of three sample processing procedures on the determination of trace REEs were discussed and the detection limits, accuracy and precision of the three methods were compared.

\section{RESULTS AND DISCUSSION}

The separation and pre-enrichment route for the determination of REEs by ICP-MS is shown in Figure 1.

\section{Matrix interference}

Matrix elements such as $\mathrm{Mg}, \mathrm{Fe}, \mathrm{Na}, \mathrm{Ca}$, etc. in rocks have an influence on the determination of REEs. First of all, triethanolamine (TEA) forms a complex with $\mathrm{Fe}, \mathrm{Mg}$ forms $\mathrm{Mg}(\mathrm{OH})_{2}$ precipitate, co-precipitating REEs onto $\mathrm{Mg}(\mathrm{OH})_{2}$, so most of $\mathrm{Fe}, \mathrm{K}$, and $\mathrm{Na}$ are separated; secondly, after adjusting the $\mathrm{pH}$ value with ammonia solution, iron precipitates as $\mathrm{Fe}(\mathrm{OH})_{3}$. REE co-precipitate with it, allowing their isolation from other major matrix elements such as $\mathrm{Mg}, \mathrm{Ca}$ and $\mathrm{Ba}$. In cation exchange enrichment, the affinity of REEs for the cation exchange resin on elution with $\mathrm{HCl}$ is much larger than in the case of other elements, so $\mathrm{K}, \mathrm{Na}$, $\mathrm{Al}, \mathrm{Ca}, \mathrm{Mg}, \mathrm{Ba}, \mathrm{Fe}$, etc. are separated by eluting with different concentrations of $\mathrm{HCl}$. In PMBP extraction enrichment, PMBP forms benzeneextractable complexes with REEs. $\mathrm{K}, \mathrm{Na}, \mathrm{Al}, \mathrm{Ca}$, $\mathrm{Mg}, \mathrm{Ba}, \mathrm{Fe}$, etc. are separated by back extraction with a mixture of formic acid and 8hydroxyquinoline. The separation and enrichment by the above three methods reduce the dilution factor and improve the accuracy of ICP-MS determination.

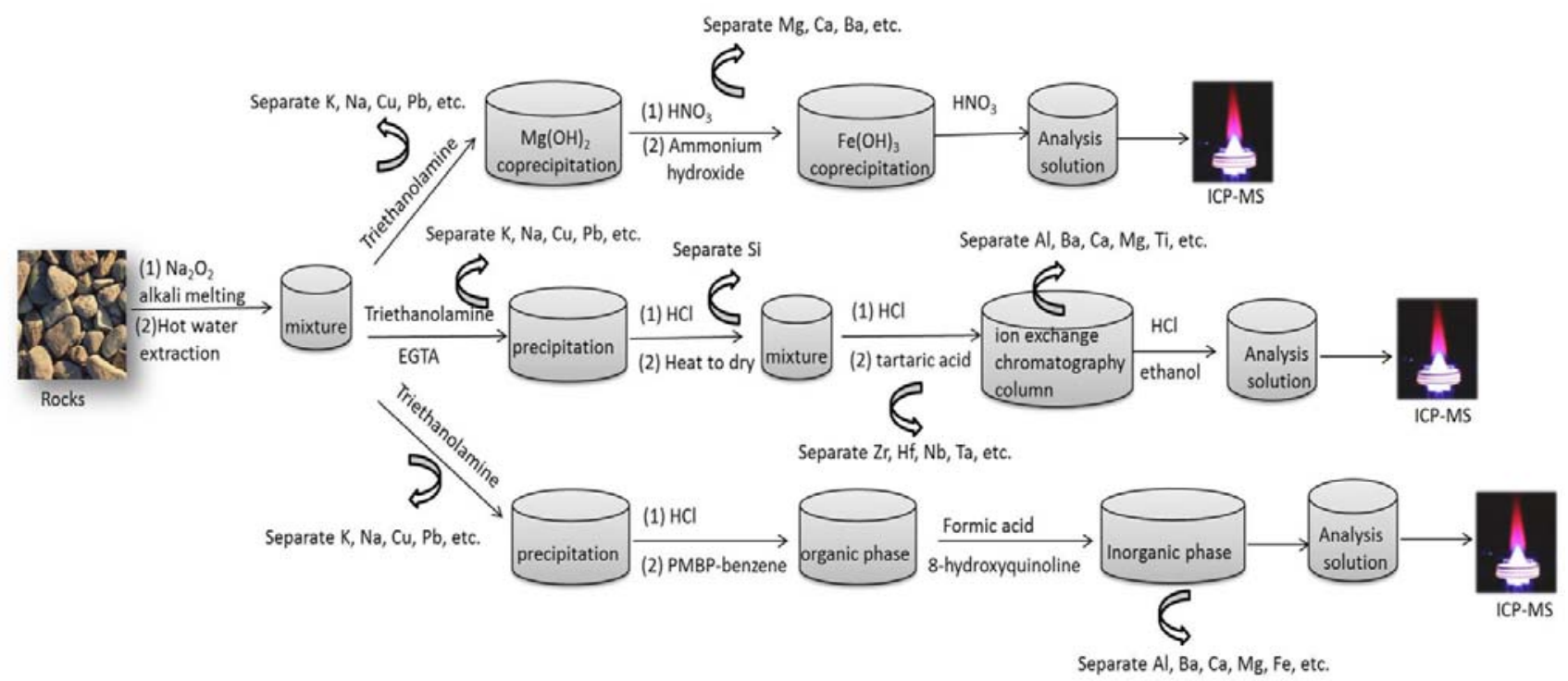

Fig. 1 - The separation and pre-enrichment route for determination of REEs by ICP-MS. 
Table 1

Calibration functions and determination coefficients of REEs

\begin{tabular}{ccc||ccc}
\hline Elements & $\begin{array}{c}\text { Calibration } \\
\text { functions }^{\mathbf{a}}\end{array}$ & $\begin{array}{c}\text { Determination } \\
\text { coefficients }\end{array}$ & Elements & $\begin{array}{c}\text { Calibration } \\
\text { functions }\end{array}$ & $\begin{array}{c}\text { Determination } \\
\text { coefficients }\end{array}$ \\
\hline $\mathrm{La}$ & $\mathrm{Y}=4299.7 \mathrm{x}+3193.5$ & 0.9992 & $\mathrm{~Tb}$ & $\mathrm{Y}=4775.1 \mathrm{x}+2257.1$ & 0.9994 \\
$\mathrm{Ce}$ & $\mathrm{Y}=4357.2 \mathrm{x}-1108.3$ & 0.9991 & $\mathrm{Dy}$ & $\mathrm{Y}=1433.8 \mathrm{x}+716.7$ & 0.9995 \\
$\mathrm{Pr}$ & $\mathrm{Y}=3057.9 \mathrm{x}-251.1$ & 0.9994 & $\mathrm{Ho}$ & $\mathrm{Y}=2001.2 \mathrm{x}+1444.4$ & 0.9991 \\
$\mathrm{Nd}$ & $\mathrm{Y}=2250.3 \mathrm{x}-446.1$ & 0.9991 & $\mathrm{Er}$ & $\mathrm{Y}=2844.7 \mathrm{x}-1217.6$ & 0.9993 \\
$\mathrm{Sm}$ & $\mathrm{Y}=3049.6 \mathrm{x}+1347.7$ & 0.9990 & $\mathrm{Tm}$ & $\mathrm{Y}=2003.2 \mathrm{x}+589.0$ & 0.9996 \\
$\mathrm{Eu}$ & $\mathrm{Y}=2942.7 \mathrm{x}+254.1$ & 0.9997 & $\mathrm{Yb}$ & $\mathrm{Y}=3237.8 \mathrm{x}-765.4$ & 0.9996 \\
$\mathrm{Gd}$ & $\mathrm{Y}=3880.2 \mathrm{x}+1662.5$ & 0.9996 & $\mathrm{Lu}$ & $\mathrm{Y}=2132.4 \mathrm{x}-917.5$ & 0.9991 \\
\hline
\end{tabular}

${ }^{\mathrm{a} X}$ : concentration in $\mu \mathrm{g} / \mathrm{L}$, Y: singnal intensity (CPS)

Table 2

Quantification limits of REEs

\begin{tabular}{|c|c|c|c|c|c|c|c|}
\hline \multirow{2}{*}{ Elements } & \multicolumn{3}{|c|}{ LOQ (mg/kg) } & \multirow{2}{*}{ Elements } & \multicolumn{3}{|c|}{ LOQ (mg/kg) } \\
\hline & $\begin{array}{l}\begin{array}{l}\text { Co- } \\
\text { precipitation }\end{array} \\
\end{array}$ & $\begin{array}{c}\text { Cation } \\
\text { exchange }\end{array}$ & $\begin{array}{l}\text { DMBP- } \\
\text { extraction }\end{array}$ & & $\begin{array}{l}\text { Co- } \\
\text { precipitation }\end{array}$ & $\begin{array}{c}\text { Cation } \\
\text { exchange }\end{array}$ & $\begin{array}{l}\text { DMBP- } \\
\text { extraction }\end{array}$ \\
\hline $\mathrm{La}$ & 0.0137 & 0.0183 & 0.0247 & $\overline{\mathrm{Tb}}$ & 0.0093 & 0.0037 & 0.0120 \\
\hline $\mathrm{Ce}$ & 0.0253 & 0.0207 & 0.0380 & Dy & 0.0067 & 0.0090 & 0.0127 \\
\hline $\operatorname{Pr}$ & 0.0093 & 0.0080 & 0.0143 & Но & 0.0030 & 0.0047 & 0.0250 \\
\hline $\mathrm{Nd}$ & 0.0057 & 0.0080 & 0.0147 & Er & 0.0150 & 0.0077 & 0.0200 \\
\hline $\mathrm{Sm}$ & 0.0067 & 0.0087 & 0.0173 & $\mathrm{Tm}$ & 0.0207 & 0.0117 & 0.0257 \\
\hline $\mathrm{Eu}$ & 0.0040 & 0.0073 & 0.0077 & $\mathrm{Yb}$ & 0.0043 & 0.0080 & 0.0187 \\
\hline $\mathrm{Gd}$ & 0.0197 & 0.0173 & 0.0380 & $\mathrm{Lu}$ & 0.0217 & 0.0123 & 0.0370 \\
\hline
\end{tabular}

\section{Mass spectrum interference}

The mass spectral interferences of REEs mainly come from oxides, polyatomic ions, and isotopes. In ICP-MS analysis, $\mathrm{BaO}$ interferes with $\mathrm{Eu}$ and LREEs oxides interfere with HREEs. In the pretreatment process, $\mathrm{Ba}$ has been separated from REEs. At the same time, after optimizing the operating parameters of the instrument, the oxide yield is less than 1\%. Therefore, the interference of $\mathrm{BaO}$ on $\mathrm{Eu}$ and the interference of LREEs oxides on HREEs are both negligible. ${ }^{23}$ According to the principle of non-interference, the determination of isotopes was performed. Therefore, ${ }^{139} \mathrm{La},{ }^{140} \mathrm{Ce}$, ${ }^{141} \mathrm{Pr},{ }^{146} \mathrm{Nd},{ }^{147} \mathrm{Sm},{ }^{151} \mathrm{Eu},{ }^{158} \mathrm{Gd},{ }^{159} \mathrm{~Tb},{ }^{163} \mathrm{Dy},{ }^{165} \mathrm{Ho}$, ${ }^{166} \mathrm{Er},{ }^{169} \mathrm{Tm},{ }^{172} \mathrm{Yb}$, and ${ }^{175} \mathrm{Lu}$ were selected as the analysis isotopes.

\section{Calibration and quantification limits}

REEs stock standard solutions were diluted step by step with $2 \% \mathrm{HNO}_{3}$ into a mixing standard series of $0.0,0.1,0.5,1.0,10.0,50.0$ and 100.0 $\mu \mathrm{g} / \mathrm{L}$. The calibration functions were obtained using optimized instrument working conditions. As shown in Table 1, the instrument response and concentration of REEs enjoy a good linear relationship in the $0.0-100.0 \mu \mathrm{g} / \mathrm{L}$ range.

The whole process blank solution $(n=12)$ was prepared according to the prescribed method, and the contents of REEs were continuously determined under the selected instrument operating parameters. The quantification limits (LOQs) were calculated from the calibration curves as the concentration equivalent to ten times the standard deviation of blank signal (dilution factor $\mathrm{DF}=250$ ). The LOQs of REEs obtained in the analysis are listed in Table 2. It can be seen from Table 1 that the LOQs of the three sample processing procedures are $0.0030-0.0253 \mathrm{mg} / \mathrm{kg}, 0.0037-$ $0.0207 \mathrm{mg} / \mathrm{kg}, 0.007-0.0380 \mathrm{mg} / \mathrm{kg}$, respectively. The detection limits obtained by co-precipitation and cation exchange are better than those of PMBP-extraction. The three sample processing procedures have good detection ability, which can well meet the requirements for the determination of REEs in rocks. 
Table 3

Concentrations determined of REEs in reference samples by ICP-MS under three methods

\begin{tabular}{|c|c|c|c|c|c|c|c|c|c|c|c|}
\hline \multirow[b]{2}{*}{ Elements } & \multirow{2}{*}{$\begin{array}{l}\text { Reference } \\
\text { samples }\end{array}$} & \multirow[b]{2}{*}{ Certified (mg/kg) } & \multicolumn{3}{|c|}{ Co-precipitation } & \multicolumn{3}{|c|}{ Cation exchange } & \multicolumn{3}{|c|}{ DMBP-extraction } \\
\hline & & & $\begin{array}{c}\text { Measured } \\
(\mathrm{mg} / \mathrm{kg})\end{array}$ & $\Delta \log C$ & RSD\% & $\begin{array}{c}\text { Measured } \\
(\mathrm{mg} / \mathrm{kg})\end{array}$ & $\Delta \log C$ & RSD\% & $\begin{array}{c}\text { Measured } \\
(\mathrm{mg} / \mathrm{kg})\end{array}$ & $\Delta \log C$ & RSD\% \\
\hline \multirow{3}{*}{$\mathrm{La}$} & GBW07108 & $15 \pm 4$ & $15 \pm 0.4$ & 0.006 & 2.35 & $15 \pm 1$ & 0.009 & 6.5 & $17 \pm 1$ & 0.049 & 9.16 \\
\hline & GBW07120 & $2.3 \pm 0.2$ & $2.2 \pm 0.1$ & -0.011 & 5.13 & $2.2 \pm 0.2$ & -0.013 & 7.56 & $2.2 \pm 0.2$ & -0.024 & 9.50 \\
\hline & GBW07121 & $25 \pm 2$ & $26 \pm 1$ & 0.010 & 3.06 & $26 \pm 1$ & 0.023 & 4.02 & $25 \pm 1$ & -0.003 & 4.78 \\
\hline \multirow{3}{*}{$\mathrm{Ce}$} & GBW07108 & $25 \pm 3$ & $25 \pm 1$ & 0.006 & 3.77 & $25 \pm 1$ & 0.003 & 3.8 & $24 \pm 1$ & -0.012 & 5.00 \\
\hline & GBW07120 & $4.6 \pm 0.4$ & $4.7 \pm 0.4$ & 0.013 & 8.09 & $4.8 \pm 0.3$ & 0.017 & 7.03 & $4.2 \pm 0.3$ & -0.037 & 5.69 \\
\hline & GBW07121 & $48 \pm 3$ & $46 \pm 2$ & -0.019 & 4.73 & $50 \pm 3$ & 0.018 & 5.46 & $45 \pm 2$ & -0.027 & 4.19 \\
\hline \multirow{3}{*}{$\operatorname{Pr}$} & GBW07108 & $3.4 \pm 0.4$ & $3.3 \pm 0.3$ & -0.010 & 7.58 & $3.3 \pm 0.1$ & -0.016 & 2.28 & $3.6 \pm 0.2$ & 0.024 & 6.03 \\
\hline & GBW07120 & $0.60 \pm 0.14$ & $0.65 \pm 0.05$ & 0.032 & 8.29 & $0.64 \pm 0.04$ & 0.028 & 7.3 & $0.56 \pm 0.05$ & -0.034 & 7.58 \\
\hline & GBW07121 & $5.8 \pm 0.8$ & $6.0 \pm 0.3$ & 0.016 & 4.29 & $5.5 \pm 0.4$ & -0.026 & 6.71 & $5.3 \pm 0.3$ & -0.038 & 5.75 \\
\hline \multirow[b]{3}{*}{$\mathrm{Nd}$} & GBW07108 & $12.0 \pm 1.0$ & $12.2 \pm 1.0$ & 0.007 & 8.56 & $12.7 \pm 0.8$ & 0.025 & 6.50 & $11.6 \pm 0.9$ & -0.014 & 7.5 \\
\hline & GBW07120 & $1.96 \pm 0.14$ & $2.01 \pm 0.11$ & 0.01 & 5.38 & $1.87 \pm 0.09$ & -0.021 & 4.44 & $1.83 \pm 0.10$ & -0.03 & 5.07 \\
\hline & GBW07121 & $21 \pm 4$ & $20 \pm 2$ & -0.011 & 8.49 & $22 \pm 1$ & 0.013 & 4.75 & $21 \pm 1$ & 0.008 & 6.45 \\
\hline \multirow{3}{*}{$\mathrm{Sm}$} & GBW07108 & $2.4 \pm 0.2$ & $2.4 \pm 0.2$ & -0.009 & 6.89 & $2.4 \pm 0.2$ & -0.003 & 6.74 & $2.3 \pm 0.1$ & -0.015 & 4.03 \\
\hline & GBW07120 & $0.40 \pm 0.05$ & $0.42 \pm 0.03$ & 0.02 & 7.12 & $0.42 \pm 0.03$ & 0.019 & 8.41 & $0.38 \pm 0.02$ & -0.021 & 4.38 \\
\hline & GBW07121 & $3.3 \pm 0.3$ & $3.2 \pm 0.1$ & -0.009 & 3.04 & $3.4 \pm 0.2$ & 0.013 & 5.68 & $3.2 \pm 0.2$ & -0.012 & 5.93 \\
\hline \multirow{3}{*}{$\mathrm{Eu}$} & GBW07108 & $0.51 \pm 0.05$ & $0.51 \pm 0.02$ & -0.004 & 3.97 & $0.52 \pm 0.03$ & 0.006 & 5.39 & $0.52 \pm 0.02$ & 0.006 & 4.37 \\
\hline & GBW07120 & $0.082 \pm 0.019$ & $0.085 \pm 0.011$ & 0.016 & 6.35 & $0.086 \pm 0.013$ & 0.021 & 6.65 & $0.076 \pm 0.004$ & -0.035 & 4.56 \\
\hline & GBW07121 & $1.0 \pm 0.2$ & $1.0 \pm 0.1$ & 0.011 & 6.17 & $1.0 \pm 0.1$ & 0.011 & 5.28 & $1.0 \pm 0.1$ & 0.011 & 4.6 \\
\hline \multirow{3}{*}{ Gd } & GBW07108 & $1.9 \pm 0.2$ & $1.9 \pm 0.1$ & 0.008 & 2.34 & $1.9 \pm 0.1$ & 0.002 & 4.73 & $1.9 \pm 0.1$ & 0.004 & 6.25 \\
\hline & GBW07120 & $0.36 \pm 0.08$ & $0.36 \pm 0.01$ & -0.006 & 3.02 & $0.35 \pm 0.03$ & -0.013 & 8.69 & $0.39 \pm 0.03$ & 0.036 & 7.46 \\
\hline & GBW07121 & $2.4 \pm 0.3$ & $2.45 \pm 0.19$ & 0.008 & 7.73 & $2.3 \pm 0.1$ & -0.011 & 5.91 & $2.6 \pm 0.2$ & 0.026 & 6.08 \\
\hline \multirow{3}{*}{$\mathrm{Tb}$} & GBW07108 & $0.35 \pm 0.05$ & $0.35 \pm 0.02$ & 0.019 & 4.81 & $0.34 \pm 0.01$ & -0.014 & 3.75 & $0.36 \pm 0.02$ & 0.011 & 6.72 \\
\hline & GBW07120 & $0.054 \pm 0.010$ & $0.057 \pm 0.004$ & 0.023 & 7.40 & $0.051 \pm 0.001$ & -0.024 & 7.51 & $0.058 \pm 0.004$ & 0.028 & 7.95 \\
\hline & GBW07121 & $0.29 \pm 0.03$ & $0.30 \pm 0.02$ & 0.019 & 5.84 & $0.28 \pm 0.01$ & -0.014 & 2.94 & $0.31 \pm 0.01$ & 0.027 & 4.1 \\
\hline \multirow[t]{2}{*}{ Dy } & GBW07108 & $1.6 \pm 0.2$ & $1.5 \pm 0.1$ & -0.016 & 7.03 & $1.5 \pm 0.1$ & -0.023 & 7.14 & $1.7 \pm 0.12$ & 0.029 & 7.64 \\
\hline & GBW07120 & $0.28 \pm 0.07$ & $0.27 \pm 0.02$ & -0.012 & 6.2 & $0.26 \pm 0.02$ & -0.032 & 5.51 & $0.27 \pm 0.01$ & -0.024 & 3.67 \\
\hline
\end{tabular}




\begin{tabular}{|c|c|c|c|c|c|c|c|c|c|c|c|}
\hline \multirow{3}{*}{ Elements } & \multirow{2}{*}{$\begin{array}{c}\text { Reference } \\
\text { samples }\end{array}$} & \multirow[b]{2}{*}{ Certified (mg/kg) } & \multicolumn{3}{|c|}{ Co-precipitation } & \multicolumn{3}{|c|}{ Cation exchange } & \multicolumn{3}{|c|}{ DMBP-extraction } \\
\hline & & & $\begin{array}{c}\text { Measured } \\
(\mathrm{mg} / \mathrm{kg})\end{array}$ & $\Delta \log C$ & RSD\% & $\begin{array}{c}\text { Measured } \\
(\mathrm{mg} / \mathrm{kg})\end{array}$ & $\Delta \log C$ & RSD\% & $\begin{array}{c}\text { Measured } \\
(\mathrm{mg} / \mathrm{kg})\end{array}$ & $\Delta \log C$ & RSD\% \\
\hline & GBW07121 & $1.52 \pm 0.14$ & $1.41 \pm 0.11$ & -0.031 & 7.53 & $1.62 \pm 0.10$ & 0.027 & 6.45 & $1.65 \pm 0.08$ & 0.036 & 5.49 \\
\hline \multirow{3}{*}{ Ho } & GBW07108 & $0.33 \pm 0.05$ & $0.32 \pm 0.02$ & -0.016 & 6.59 & $0.31 \pm 0.02$ & -0.028 & 5.49 & $0.35 \pm 0.03$ & 0.027 & 8.25 \\
\hline & GBW07120 & $(0.045)$ & $0.047 \pm 0.004$ & 0.015 & 8.88 & $0.043 \pm 0.003$ & -0.021 & 7.06 & $0.044 \pm 0.002$ & -0.011 & 5.03 \\
\hline & GBW07121 & $0.27 \pm 0.03$ & $0.28 \pm 0.01$ & 0.02 & 4.9 & $0.28 \pm 0.01$ & 0.01 & 3.45 & $0.29 \pm 0.02$ & 0.028 & 8.22 \\
\hline \multirow{3}{*}{$\mathrm{Er}$} & GBW07108 & $1.0 \pm 0.2$ & $1.0 \pm 0.1$ & 0.009 & 6.44 & $1.1 \pm 0.1$ & 0.024 & 9.92 & $1.1 \pm 0.1$ & 0.027 & 8.86 \\
\hline & GBW07120 & $(0.17)$ & $0.18 \pm 0.01$ & 0.018 & 6.32 & $0.16 \pm 0.01$ & -0.02 & 5.34 & $0.16 \pm 0.01$ & -0.021 & 5.2 \\
\hline & GBW07121 & $0.76 \pm 0.08$ & $0.73 \pm 0.05$ & -0.021 & 6.53 & $0.73 \pm 0.05$ & -0.02 & 6.57 & $0.80 \pm 0.07$ & 0.023 & 9.33 \\
\hline \multirow{3}{*}{$\mathrm{Tm}$} & GBW07108 & $0.17 \pm 0.04$ & $0.18 \pm 0.01$ & 0.016 & 8.19 & $0.16 \pm 0.01$ & -0.018 & 7.22 & $0.18 \pm 0.01$ & 0.022 & 5.61 \\
\hline & GBW07120 & $(0.024)$ & $0.025 \pm 0.002$ & 0.02 & 7.15 & $0.025 \pm 0.001$ & 0.023 & 5.71 & $0.026 \pm 0.002$ & 0.042 & 6.52 \\
\hline & GBW07121 & $0.11 \pm 0.02$ & $0.11 \pm 0.01$ & 0.012 & 8.3 & $0.10 \pm 0.01$ & -0.033 & 9.21 & $0.11 \pm 0.01$ & 0.018 & 8.8 \\
\hline \multirow{3}{*}{$\mathrm{Yb}$} & GBW07108 & $0.90 \pm 0.11$ & $0.86 \pm 0.04$ & -0.021 & 4.99 & $0.82 \pm 0.08$ & -0.042 & 9.27 & $1.00 \pm 0.05$ & 0.048 & 5.05 \\
\hline & GBW07120 & $0.15 \pm 0.05$ & $0.15 \pm 0.01$ & -0.012 & 4.79 & $0.16 \pm 0.01$ & 0.023 & 7.33 & $0.16 \pm 0.01$ & 0.03 & 6.28 \\
\hline & GBW07121 & $0.69 \pm 0.08$ & $0.72 \pm 0.04$ & 0.018 & 5.73 & $0.70 \pm 0.04$ & 0.004 & 5.57 & $0.77 \pm 0.04$ & 0.045 & 5.12 \\
\hline \multirow{3}{*}{$\mathrm{Lu}$} & GBW07108 & $0.14 \pm 0.03$ & $0.15 \pm 0.01$ & 0.026 & 5.81 & $0.14 \pm 0.01$ & -0.01 & 6.19 & $0.14 \pm 0.01$ & -0.013 & 4.43 \\
\hline & GBW07120 & $0.023 \pm 0.007$ & $0.022 \pm 0.002$ & -0.023 & 8.86 & $0.022 \pm 0.002$ & -0.026 & 8.96 & $0.021 \pm 0.001$ & -0.038 & 6.28 \\
\hline & GBW07121 & $0.11 \pm 0.01$ & $0.12 \pm 0.01$ & 0.024 & 6.29 & $0.11 \pm 0.01$ & 0.007 & 6.71 & $0.12 \pm 0.01$ & 0.027 & 8.12 \\
\hline
\end{tabular}

Values are for mean \pm standard deviation of twelve replicate measurements $(\mathrm{n}=12)$. 


\section{Comparison of accuracy and precision}

According to the specified method, the national first-class reference samples GBW07108 (marly limestone), GBW07120 (limestone), and GBW07121 (granite gneiss) were measured. For each analyzed reference sample, the average determined value $(n=12)$, certified value, accuracy results $(\Delta \log C)$ and relative standard deviation $(\% \mathrm{RSD})(\mathrm{n}=12)$ were collected in Table 3.

As shown in Table 3 and Fig. 2, the measured values of HREEs after cation exchange enrichment were lower than the certified values. This may be due to the high distribution coefficient of REEs in strongly acidic cation exchange resin and 1-2 $\mathrm{mol} / \mathrm{L} \mathrm{HCl}$. The distribution coefficient decreases with the increase of the atomic number of REEs, the distribution coefficient of LREEs is greater than that of HREEs, resulting in incomplete exchange of HREEs, which results in lower measurement results.

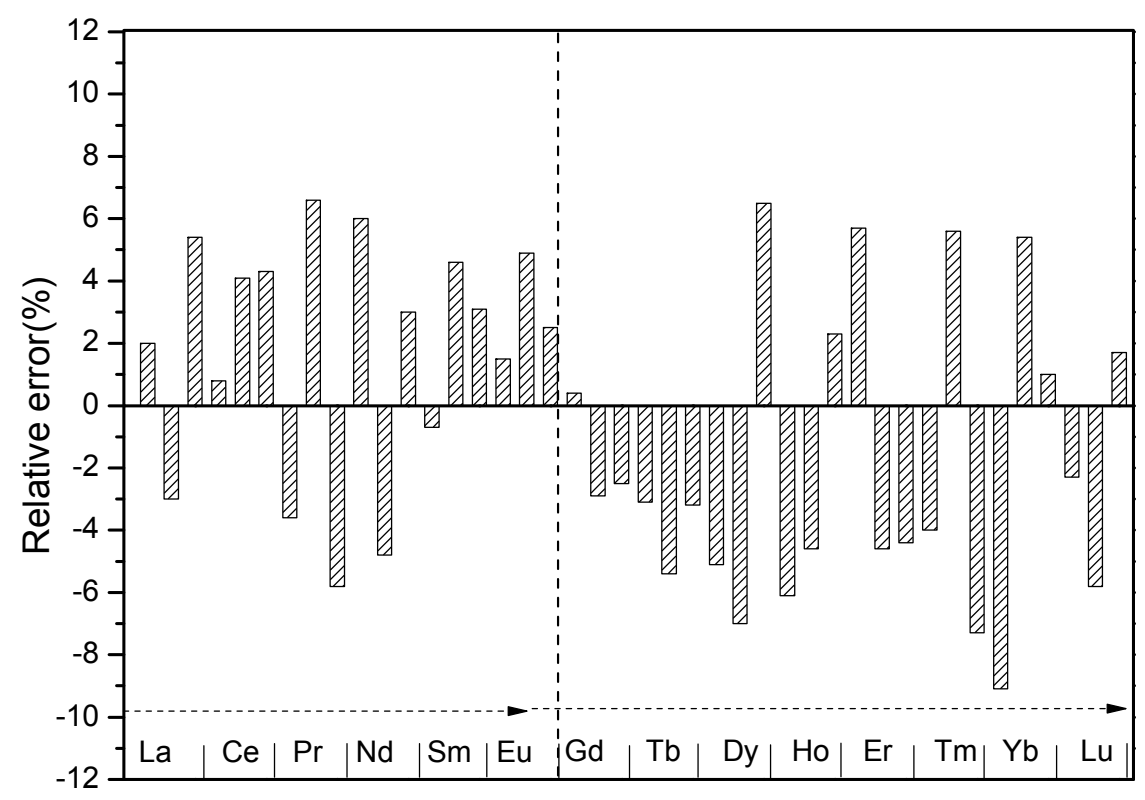

Rare earth elements

Fig. 2 - Schematic diagram of the accuracy of cation exchange.

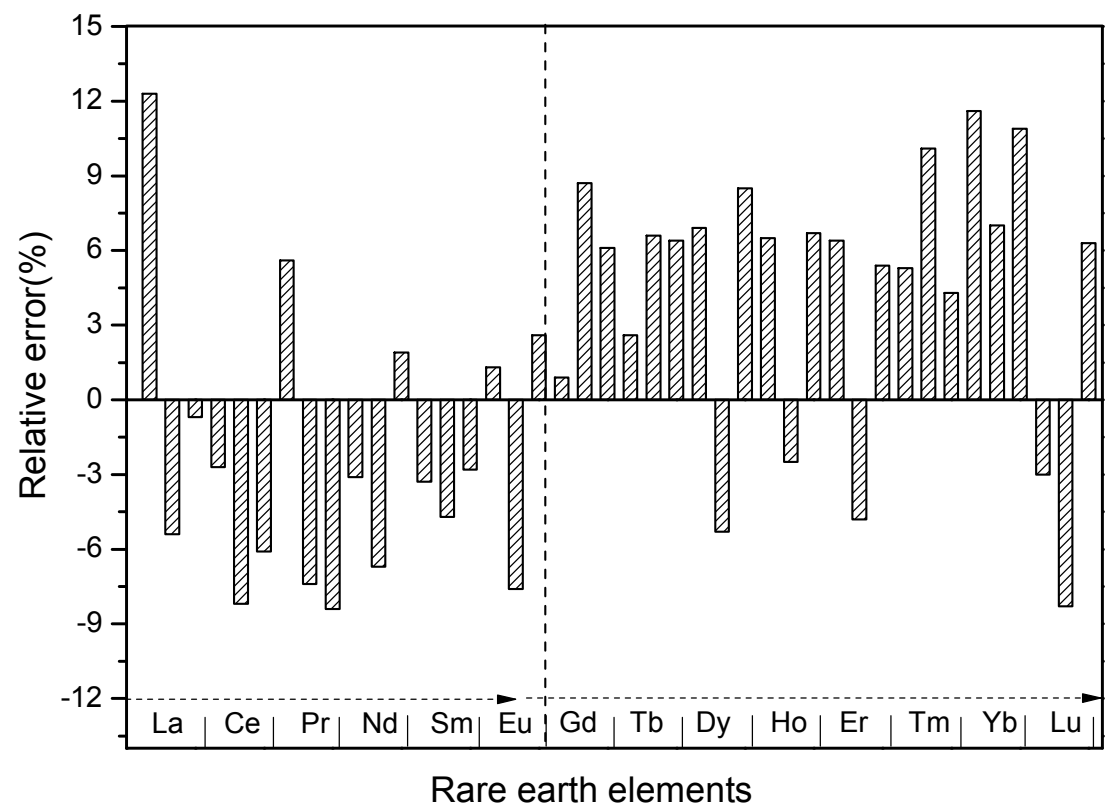

Fig. 3 - Schematic diagram of the accuracy of DMBP-extraction enrichment. 


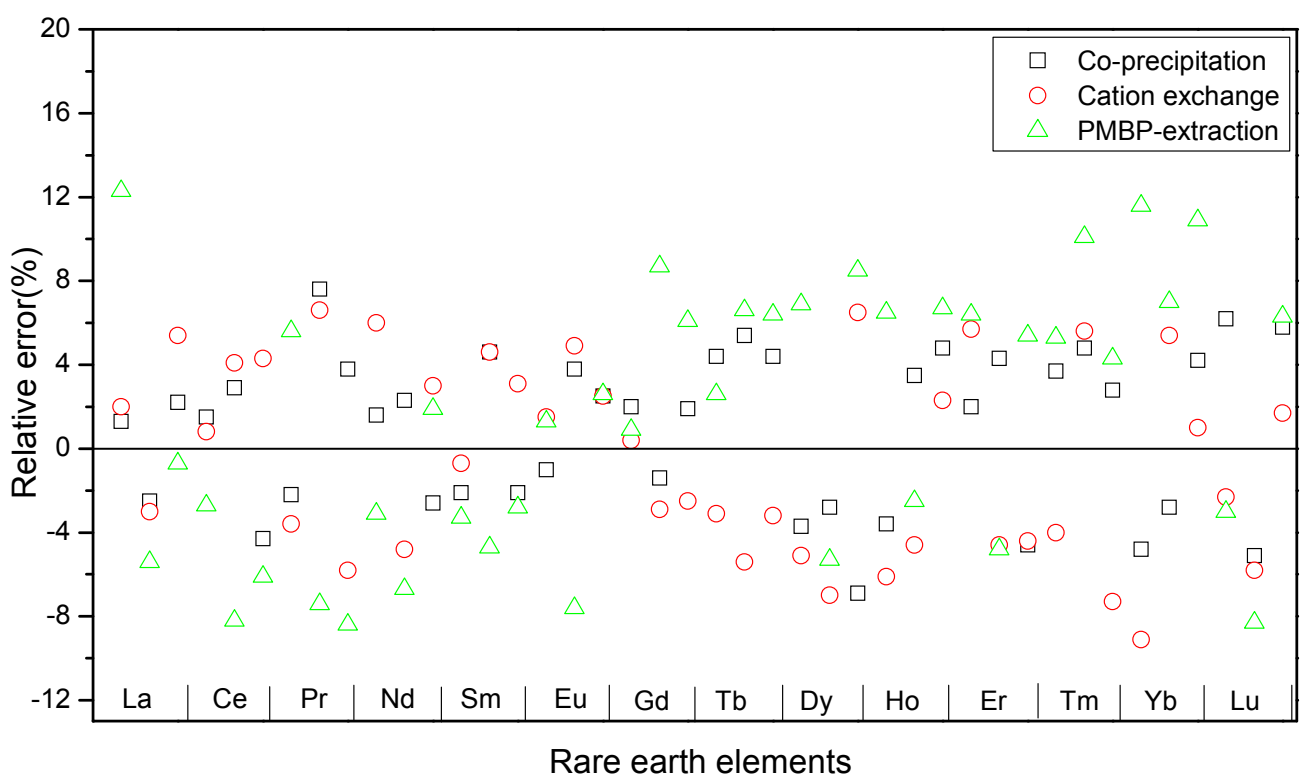

Fig. 4 - Comparison of the accuracy of three different pre-processing methods.

The measured values of LREEs by the PMBPextraction were lower than the certified values, as shown in Table 3 and Figure 3. The reason may be that due to the "lanthanum shrinkage" of REEs, the ion radius gradually decreases from $\mathrm{La}$ to $\mathrm{Lu}$. Therefore, the basicity of lanthanides gradually decreases from $\mathrm{La}$ to $\mathrm{Lu}$. When $\mathrm{pH}<5$, the extraction of LREEs may be incomplete, while HREEs can be completely extracted; when $\mathrm{pH}>5$, LREEs are completely eluted, while HREEs are somewhat less. Most of the very low values in the reference samples selected in this article are in HREEs. Therefore, the $\mathrm{pH}$ value is set to 4.5 to ensure the complete extraction of low content HREEs, which may lead to incomplete extraction of some LREEs, making its measurement results low. ${ }^{24}$

The relative error (\%RE) was adopted to evaluate the accuracy of twelve replicates of each sample. The concentrations of REEs by coprecipitation, cation exchange and PMBP-extraction were compared with certified values. The relative standard deviations of the levels of REEs determined after sample co-precipitation ranged from -6.9 to $7.6 \%$, while for cation exchange sample processing they varied from -9.1 to $6.6 \%$ and extended from -8.4 to $12.3 \%$ when PMBP extraction was applied. All the determination data by the three methods were reasonable and acceptable. The comparison of experimental results showed better accuracy after sample processing by co-precipitation and cation exchange than when using PMBP extraction (Fig. 4).

Results accuracy was also evaluated by the quality test proposed by the International Geological
Correlation Programme (IGCP), ${ }^{25}$ which compares the differences between obtained and recommended values by the expression of $\Delta \log C\left(\log C_{s}-\log C_{i}\right)$, where $C_{i}$ and $C_{s}$ are the certified and measured value, respectively. According to IGCP criteria, $\Delta \log$ $\mathrm{C}$ of the reference samples analyzed in this work would be between -0.05 and 0.05 for REEs. The results in Table 3 showed that $\triangle \log C$ of REEs determination were $-0.031-0.032$ for coprecipitation and -0.042-0.028 for cation exchange and -0.038-0.049 for PMBP-extraction, which shows good accuracy. It can be deduced that all the three sample processing procedures are adequate for geochemical mapping application. The precision of twelve replicates of each sample is expressed as the relative standard deviation (\%RSD). It can be seen from Table 3 that the \%RSD values of REEs determination were lower than $8.88 \%$ for coprecipitation and lower than $9.92 \%$ for cation exchange and lower than $9.50 \%$ for PMBPextraction. Consequently, all three methods developed in this study are demonstrated to be a valid method for determining REEs in rocks.

\section{EXPERIMENTAL}

\section{Instruments and operation conditions}

An ICP-MS (X Series II, Thermofisher Scientific, USA) was used for the determination of trace REEs. The sensitivity, oxide yield $(<1.0 \%)$ and double charge yield $(<3.0 \%)$ were adjusted by the tuning solution. Details of the instrument and the operating parameters are summarized in Table 4. 
Table 4

\begin{tabular}{ll}
\multicolumn{2}{c}{ Operating conditions of ICP-MS } \\
\hline Item & Parameter \\
\hline RF power $(\mathrm{W})$ & 1300 \\
Nebulizer gas flow $\left(\mathrm{L} \cdot \mathrm{min}^{-1}\right)$ & 0.8 \\
Cooling gas flow $\left(\mathrm{L} \cdot \mathrm{min}^{-1}\right)$ & 13.5 \\
Auxiliary gas flow $\left(\mathrm{L} \cdot \mathrm{min}^{-1}\right)$ & 0.78 \\
Sampling depth $(\mathrm{mm})$ & 13 \\
Dwell time $(\mathrm{ms})$ & 10 \\
Integration time $(\mathrm{s})$ & 15 \\
Rising speed $\left(\mathrm{mL} \cdot \mathrm{min}^{-1}\right)$ & 1.0 \\
Sample cone $($ Aperture $/ \mathrm{mm})$ & Nickel $(1.0)$ \\
Skimmer cone $($ Aperture $/ \mathrm{mm})$ & Nickel $(0.7)$ \\
\hline
\end{tabular}

\section{Reagents and solutions}

Reference samples GBW07108 (marly limestone, IGGE, China), GBW07120 (limestone, IGGE, China), and GBW07121 (granite gneiss, IGGE, China) were used for method validation; hydrochloric acid (36.0-38.0\%), hydrofluoric acid $(\geq 40.0 \%)$, nitric acid $(65.0-68.0 \%)$, sodium peroxide $(\geq 95.0 \%)$, triethanolamine (TEA) $(\geq 99.0 \%)$, ethylene glycol-bis ( $\beta$-aminoethyl ether)-N,N, $\mathrm{N}^{\prime}, \mathrm{N}^{\prime}$-tetraacetic acid (EGTA) ( $\geq 99.0 \%$ ), ammonium chloride $(\geq 99.8 \%)$, ammonia (25.0-28.0\%), magnesium chloride $(\geq 98.0 \%)$, tartaric acid ( $\geq 99.5 \%$ ), anhydrous ethanol ( $\geq 99.8 \%$ ), acetic acid ( $\geq 99.8 \%)$, sodium acetate ( $\geq 95.0 \%)$, PMBP $(\geq 98.0 \%)$, benzene $(\geq 99.8 \%)$ and 8-hydroxyquinoline ( $\geq 99.5 \%)$ (Sinopharm Chemical Reagent Co. Ltd, China) were all analytical grade reagent; tuning solution was purchased from Thermofisher Scientific (USA); AG 50W-X8 hydrogen type strong cation exchange resin $(0.38-0.76 \mu \mathrm{m})$ and Poly-Prep polypropylene separation column $(0.8 \mathrm{~cm} * 4 \mathrm{~cm})$ were purchased from Beijing Fuxing Chemical Industry Co. Ltd (China).

Standard solutions used to build the ICP-MS calibration curves were prepared by the appropriate dilution of stock standard solutions containing $100 \mathrm{mg} / \mathrm{L}$ REEs (IGGE, China) in $2 \%(\mathrm{v} / \mathrm{v}) \mathrm{HNO} 3 ;{ }^{103} \mathrm{Rh}$ used as internal standard solution was prepared by the appropriate dilution of stock standard solutions (IGGE, China) in 2\% (v/v) HNO3. All solutions were prepared using high purity water $(18.2 \mathrm{M} \Omega \mathrm{cm}$ resistivity) obtained from GN-RO-500 Total Water System (Shuangfeng, Beijing, China).

\section{Separation and pre-enrichment methods}

\subsection{Method for co-precipitation of $\mathrm{Mg}(\mathrm{OH})_{2}$ and $\mathrm{Fe}(\mathrm{OH})_{3}$}

$0.2000 \mathrm{~g}$ sample, $2.0 \mathrm{~g} \mathrm{Na}_{2} \mathrm{O}_{2}$ were added to the corundum crucible, mixed, then $1.0 \mathrm{~g} \mathrm{Na}_{2} \mathrm{O}_{2}$ was added to the surface of the sample and melted at $700{ }^{\circ} \mathrm{C}$ in muffle furnace for $15 \mathrm{~min}$. After cooling to room temperature, the mixture was transferred into a beaker containing $5 \mathrm{~mL}$ TEA, $50 \%$ solution. $30 \mathrm{~mL}$ hot water were added for extraction, followed by $5 \mathrm{~min}$ heating, and crucible rinsing. The mixture was centrifuged at $3200 \mathrm{r} / \mathrm{min}$ for $3 \mathrm{~min}$, the remaining liquid discarded, $1 \mathrm{~mL}$ $5 \% \mathrm{HNO} 3$ was added to dissolve the precipitate, then $10 \mathrm{~mL}$ pure water were added. The $\mathrm{pH}$ was adjusted with $50 \% \mathrm{NH}_{3}$ to precipitate iron hydroxide, followed by water addition to $25 \mathrm{~mL}$, and $10 \mathrm{~mL} \mathrm{NH}_{4} \mathrm{Cl}-\mathrm{NH}_{3}$ buffer solution $(\mathrm{pH}=9)$. The resulting mixture was centrifuged at $3200 \mathrm{r} / \mathrm{min}$ for $3 \mathrm{~min}$, the liquid was discarded, another $35 \mathrm{~mL}$ pure water were added and $0.5 \mathrm{~mL}$ ammonia. After centrifugation, the liquid was discarded, $1 \mathrm{~mL}$ nitric acid was added to dissolve the precipitate, and made up to $25 \mathrm{~mL}$ with water.

\subsection{Method for cation exchange}

The alkali melting stage was the same as in Section 3.3.1. After cooling to room temperature, the mixture was transferred into a beaker containing $10 \mathrm{~mL}$ TEA, $5 \mathrm{~mL}$ EGTA. $30 \mathrm{~mL}$ hot water were added for extraction, followed by crucible rinsing, dilution with water to $100 \mathrm{~mL}$, boiling for $5 \mathrm{~min}$. After cooling and filtering, the precipitate was washed with $2 \% \mathrm{NaOH}$ and dissolved with hot 1: $1 \mathrm{HCl}$, heated to dryness. $3 \mathrm{~mL} \mathrm{HCl}$ were added to wet the residue, and mixed with $2 \mathrm{~g}$ tartaric acid and $30 \mathrm{~mL}$ water, then heated for complete dissolution. The solution was transferred to an ion exchange chromatography column and run through the column at a rate of $0.5-0.8 \mathrm{~mL} / \mathrm{min}$. $\mathrm{Fe}, \mathrm{Al}, \mathrm{Ca}$, etc. were rinsed with $2 \mathrm{~mol} / \mathrm{L} \mathrm{HCl}-20 \% \mathrm{C}_{2} \mathrm{H}_{5} \mathrm{OH}$. The REEs were leached with $3 \mathrm{~mol} / \mathrm{L} \mathrm{HCl}-20 \% \mathrm{C}_{2} \mathrm{H}_{5} \mathrm{OH}$. The REEs eluate was heated and evaporated to $10 \mathrm{~mL}$, and diluted to $25 \mathrm{~mL}$.

\subsection{Method for PMBP-extraction enrichment}

The alkali melting stage was the same as in Section 3.3.1. After cooling to room temperature, the mixture was transferred into a beaker containing $5 \mathrm{~mL}$ TEA. $30 \mathrm{~mL}$ hot water were added for extraction, followed by crucible rinsing, dilution with water to $100 \mathrm{~mL}$, and boiling for $5 \mathrm{~min}$. After cooling and filtering, the precipitate was washed with $2 \%$ $\mathrm{NaOH}$ and dissolved with hot 1: $1 \mathrm{HCl} ; 5 \% \mathrm{HCl}$ was used to adjust the $\mathrm{pH}$ to about 5 , then $5 \mathrm{~mL}$ acetic acid-sodium acetate buffer solution $(\mathrm{pH}=4.5)$ were added, and $15 \mathrm{~mL} 0.01 \mathrm{~mol} / \mathrm{L}$ PMBP- $\mathrm{C}_{6} \mathrm{H}_{6}$ solution. Extraction was performed for $1 \mathrm{~min}$, the aqueous layer was discarded. $15 \mathrm{~mL}$ formic acid-8hydroxyquinoline mixtures were added in the organic phase for back extraction, phases were mixed for $1 \mathrm{~min}$; the organic phase was discarded, and the aqueous phase was diluted to $25 \mathrm{~mL}$.

\section{CONCLUSIONS}

In this paper, the sample processing procedures of $\mathrm{Mg}(\mathrm{OH})_{2}$ and $\mathrm{Fe}(\mathrm{OH})_{3}$ co-precipitation, cation exchange and PMBP-extraction were proposed to separate REEs from matrix elements to eliminate matrix interference and mass spectrum interferences. Sample processing by co-precipitation and cation exchange gave better results in terms of accuracy than PMBP-extraction. According to the quality criteria test proposed by IGCP, $\triangle \log C$ of all REEs determinations are between -0.05 and 0.05 , demonstrating good accuracy. It can be deduced 
that all three sample processing procedures are adequate considering geochemical mapping application. The \%RSD values of the three sample processing procedures were lower than $10 \%$, performing good precision. Consequently, all three methods can be applied for the determination of REEs in rocks.

Acknowledgements. The authors acknowledge financial support from the Project of China Geological Survey (grant number DD20191014)

\section{REFERENCES}

1. M. P. Smith, K. Moore, D. Kavecsánszki, A. A. Finch, J. Kynicky and F. Wall, Geosci. Front., 2016, 7, 315-334.

2. T. P. Rao and V. M. Biju, Crit. Rev. Anal. Chem., 2000, 30, 179-220.

3. N. M. Raut, L. S. Huang, S. K. Aggarwal and K. C. Lin, Spectrochim. Acta B., 2003, 58, 809-822.

4. M. K. Behrens, J. Muratli, C. Pradoux, Y. Wu, P. Böning, H. J. Brumsack and K. Pahnke, Mar. Chem., 2016, 186, $110-120$.

5. S. J. Ramos, G. S. Dinali, C. Oliveira, G. C. Martins, C. G. Moreira, J. O. Siqueira and L. R. G. Guilherme, Curr. Pollution Rep., 2016, 2, 28-50.

6. Y. Li, W. Guo, Z. Wu, L. Jin, Y. Ke, Q. Guo and S. Hu, Microchem. J., 2016, 126, 194-199.

7. K. Pyrzynska, A. Kubiak and I. Wysocka, Talanta, 2016, 154, 15-22.

8. A. S. Abdel-Haleem, A. Sroor, S. M. El-Bahi and E. Zohny, Appl. Radiat. Isotopes, 2001, 55, 569-573.

9. S. M. B. Oliveira, F. E. Larizzatti, D. I. T. Fávaro, S. R. D. Moreira, B. P. Mazzilli and E. L. Piovano, J. Radioanal. Nucl. Ch., 2003, 258, 531-535.
10. B. A. Wiethan, P. C. Nascimento, A. N. Colim, A. F. Guarda, F. R. Adolfo, M. B. Rosa, L. M. Carvalho and D. Bohrer, Anal. Lett., 2019, 52, 2057-2068.

11. P. Roy, V. Balaram, A. Kumar, M. Satyanarayanan and T. G. Rao, Geostand. Geoanal. Res., 2007, 31,261-273.

12. F. G. Pinto, R. E. Junior and T. D. Saint'Pierre, Anal. Lett., 2012, 45, 1537-1556.

13. F. G. Pinto, F. G. Lepri, T. D. Saint'Pierre, J. B. B. Silva, L. M. Costa and A. J. Curtius, Anal. Lett., 2010, 43, 949-959.

14. A. A. Gorbatenko and E. I. Revina, Inorg. Mater, 2015, 51, 1375-1388.

15. S. Y. E. Karakaş, O. Gaga, A. Doğangün and S. G. Tuncel, Anal. Lett., 2004, 37, 2701-2709.

16. K. Nakayama and T. Nakamura, Anal. Sci., 2005, 7, 815822 .

17. I. Nakai, Y. Terada, M. Itou and Y. Sakurai, J. Synchrotron Radiat., 2001, 8, 1078-1081.

18. R. Biddau, M. Bensimon, R. Cidu and A. Parriaux, Chem. Erde-Geochem., 2009, 69, 327-339.

19. M. He, B. Hu and Z. Jiang, Anal. Chim. Acta., 2005, 530, 105-112.

20. S. Wu, M. He, B. Hu and Z. Jiang, Microchim. Acta., 2007, 159, 269-275.

21. Z. Arslan, T. Oymak and J. White, Anal. Chim. Acta., 2018, 100, 18-28.

22. M. S. Navarro, S. Andrade, H. Ulbrich, C. B. Gomes and V. A. V. Girardi, Geostand. Geoanal. Res., 2008, 32, 167-180.

23. L. Qi, M. Zhou, J. Malpas and M. Sun, Geostand. Geoanal. Res., 2005, 29, 131-141.

24. L. Li, G. Ma, J. Wang and Z. Qu, "Rock Mineral Analysis", third edition, Geological Publishing House, Beijing, China, 1991, p.673-689.

25. A. G. Darnley, A. Bjorklund, B. Bolviken, N. Gustarsson, P. V. Koval, J. V. Plant, A.Streenjelt, M. Tauchid and M. Xuijing. Final Report of IGCP Project 259. Paris, France: United Nations Educational, Science and Cultural Organization (UNESCO), 1995, 122-125. 
